\title{
OS RIBEIRINHOS NO ARQUIPÉLAGO DE MARAJÓ E A LUTA PELA PERMANÊNCIA NO TERRITÓRIO TRADICIONALMENTE HABITADO
}

The riverside people in the Marajó archipelago and the struggle for permanence in the traditionally inhabited territory

\author{
Eliane Miranda Costa \\ Doutora em Antropologia. Universidade Federal do Pará, Campus \\ Universitário do Marajó-Breves, Faculdade de Educação e \\ Ciências. Humanas, Breves, Brasil \\ elyany2007@hotmail.com \\ https://orcid.org/0000-0001-6747-4639 \\ Vivianne Nunes da Silva Caetano \\ Doutora em Antropologia Universidade Federal do Pará, Campus \\ Universitário do Marajó-Breves, Faculdade de Educação e Ciência \\ Humanas, Breves, Brasil \\ vns@ufpa.br \\ https://orcid.org/0000-0003-3808-7618
}

A lista completa com informações dos autores está no final do artigo

\section{RESUMO}

O arquipélago de Marajó desde a colonização tem sido palco de intensas e sucessivas disputas entre diferentes grupos pela ocupação e usufruto da terra e riquezas naturais. Neste estudo, evidencia-se a luta dos ribeirinhos, um grupo social do rio Mapuá, município de Breves, Marajó, Pará, pelo acesso, uso e permanência no território tradicionalmente habitado. Em conflito com os empresários da madeira, os ribeirinhos, ameaçados de serem expulsos, requereram junto ao governo federal a criação de uma Reserva Extrativista, a Resex/Mapuá, como condição para permanecerem em seu território. Seguindo os pressupostos da pesquisa qualitativa, procuramos conhecer aspectos desse conflito, assim como discutir sobre a Resex e o uso do território na interface com a política territorial do Estado. Os dados foram coletados por meio de entrevistas semiestruturadas e análise documental. Tendo por referência o campo socioantropológico em uma perspectiva interdisciplinar, analisamos os dados empíricos, os quais nos levam a evidenciar que a Resex-Mapuá, para os ribeirinhos, constitui-se em uma tática política de afirmação e reafirmação do direito de permanecer no território que tradicionalmente habitam e costuram seus modos de vida.

PALAVRAS-CHAVE: Questão agrária. Unidade de conservação. Povos tradicionais. Território Amazônico. Mapuá.

\begin{abstract}
The Marajó archipelago since colonization has been the stage of intense and successive disputes between different groups for the occupation and enjoyment of the land and natural resources. In this study, we highlight the struggle of the riverside people, a social group of the Mapuá River, municipality of Breves, Marajó, Pará State, Brazil, for access, use and permanence in the traditionally inhabited territory. In conflict with the wood businessmen, the riverside people threatened to be expelled, requested from the federal government the creation of an Extractive Reserve, Resex/Mapuá, as a condition to stay in their territory. Following the assumptions of qualitative research, we searched about the aspects of this conflict, as well as discuss the Resex and the use of territory in the interface with the territorial policy of the State. Data were collected through semi-structured interviews and document analysis. Having as theoretical reference the socio-anthropological field in an interdisciplinary perspective, we analyze the empirical data, which lead us to show that Resex-Mapuá, for the riverside people, constitutes a political tactic of affirmation and reaffirmation of the right to stay in the territory that traditionally inhabits and sew their way of life.
\end{abstract}

KEYWORDS: Agrarian debate. Conservation unit. Traditional people. Amazon Territory. Mapuá 


\section{INTRODUÇÃO}

Neste texto, tratamos da luta dos povos ribeirinhos ${ }^{1}$ do rio Mapuá, município de Breves, Arquipélago de Marajó, estado do Pará, pelo acesso, uso e permanência no território tradicionalmente habitado, praticado e partilhado. $\mathrm{Na}$ área banhada por este rio, em 2005, por meio de Decreto Presidencial, foi crida a Reserva Extrativista Mapuá (Resex/Mapuá), a partir da reivindicação das comunidades locais, em função de conflitos com empresários da madeira, que se intitulavam donos do Mapuá e impediam aos ribeirinhos o acesso a terra e ao rio. A finalidade aqui é conhecer aspectos desse conflito, assim como discutir sobre a Resex e o uso do território na interface com a política territorial do Estado.

Para fomentar essa discussão elencamos as seguintes questões-norteadoras: Como o Estado lida com a questão ambiental e agrária da Amazônia, em especial no Marajó? Com a criação de Unidade de Conservação (UC) os conflitos históricos são superados? No rio Mapuá, a criação da Resex permitiu acabar com os conflitos entre os ribeirinhos e madeireiros? Que desafios esta UC impõe aos ribeirinhos no Mapuá? O estudo busca fundamentos teóricos no campo socioantropológico em uma perspectiva interdisciplinar e analisa o conflito e a UC a partir da noção de território tradicional, aqui interpretado como uma categoria plural e dinâmica, que não se reduz a espaço geográfico, bem como a poder e simbolismo. Território abarca experiências, vivências, sentidos e significados estabelecidos pelos povos com o ambiente nos contextos e temporalidades distintas (ACSERALD, 2010; ACEVEDO-MARIN, 2015; COSTA, 2018).

A pesquisa segue pelo rastro da abordagem qualitativa baseada em fontes bibliográficas, documentais e trechos de entrevistas semiestruturadas realizadas com ribeirinhos que moram na área da Resex. A base bibliográfica compreende diferentes produções de vários autores, entre os quais, destacamos: Acevedo-Marin (2015), Almeida (2008), Litlle (2002), Diegues (2001), privilegiando o aspecto interdisciplinar. Os documentos consultados foram dois, a saber: Plano de Uso da Resex-Mapuá e o Plano de Desenvolvimento Territorial Sustentável do Arquipélago do Marajó (PDTSAM); as entrevistas foram realizadas com 10 ribeirinhos, diretamente envolvidos com o movimento

${ }^{1} \mathrm{O}$ termo Ribeirinhos, entendido como uma das formas para designar povos tradicionais, passa por deslocamentos em seu significado desde 1988, com isso deixou de enfatizar apenas os "sujeitos biologizados", e passou a levar em consideração a autodefinição, coletividade dos agentes sociais, os critérios políticos organizativos de variados grupos (DOURADO, 2010). 
de luta pela defesa do território. Neste texto, fazemos uso de trechos de algumas dessas entrevistas, conforme os objetivos traçados. Esclarecemos que os interlocutores estão identificados no corpo do texto com nomes fictícios, de modo assegurar o sigilo ético.

A combinação dos dados empíricos e base teórica proporcionou a organização deste texto em dois tópicos, além desta introdução e considerações, na qual destacamos ser a Resex-Mapuá, tática política para garantir aos ribeirinhos o direito de acesso, uso e permanência do território que tradicionalmente habitam. No tópico a seguir, com base em uma revisão teórica, destacamos aspectos da política ambiental do país, com ênfase na questão agrária da Amazônia, e, por conseguinte, aos desafios para o estado e à população tradicional. No último tópico, a partir dos dados empíricos tecemos análises sobre a Resex/Mapuá e o uso do território, evidenciando a questão do direito e dos conflitos gerados antes e após a criação desta UC. Na perspectiva local, a referida UC configura-se como principal estratégia das comunidades para terem o direito coletivo de continuar vivendo e trabalhando no território que tradicionalmente tem produzido e forjado seus modos de vida.

\section{O ESTADO BRASILEIRO E A POLÍTICA AMBIENTAL: A QUESTÃO AGRÁRIA E A SUSTENTABILIDADE DO TERRITÓRIO AMAZÔNICO}

A Amazônia chama atenção de países do mundo inteiro tanto por seu aspecto natural, considerado um dos maiores patrimônios da biodiversidade do planeta, importante para estabilizar o clima global, entre outros interesses, quanto por sua sociedade e intervenções políticas, vistas como responsáveis por ações nocivas à região. Em que pese a contradição e polêmica que essa perspectiva envolve, importa sinalizar aqui, ser esta região objeto de interesses patrimonialistas, em particular a Amazônia Oriental, que desde à colonização e seu sistema sesmarial, privilegiam seguimentos sociais específicos, o que contribui com a profunda desigualdade social.

Dessa política herda-se a base de um dos dois projetos de desenvolvimento rural na Amazônia, indicado por Costa (2005), que configuram a questão agrária nessa região. Costa (2005), argumenta que há na Amazônia dois projetos de desenvolvimento rural, mas, que se diferenciam "nas formas voltado para absorção do capital natural [...], na intensidade de uso do capital humano e social e nas proporções de uso do capital físico e 
trabalho" (COSTA, 2005, p. 133). Em outras palavras, tem-se um projeto preocupado com absorção do capital natural, chamado por Costa (2005) de latifundiário-monocultural, formado pela conjunção entre propriedade latifundiária, trabalho assalariado e produção homogênea de gado e grãos (comodities).

Podemos dizer que na área de floresta à exploração da madeira, bem como de outros recursos naturais, segue a lógica desse modelo para fins econômicos. Trata-se de um projeto que implica em riscos consideráveis para o ambiente e, em função do lucro, pressupõe um elevado processo produtivo que pode implicar em profundo desequilíbrio nos circuitos vitais da natureza, o que também implica em prejuízos à população local (COSTA, 2005; ACEVEDO-MARIN, 2015).

O segundo modelo proposto por Costa (2005), é chamado de familiar-policultural, formado por grupos familiares, como os ribeirinhos, pequenos agricultores, entre outros grupos tradicionais, que fazem uso de atividades diversificadas, que em comparação ao primeiro grupo oferecem baixo risco para o ambiente. Cabe observar que os grupos familiares diferentemente dos latifundiários, empresários (representantes do primeiro projeto, cuja relação com o ambiente é de exploração em vista do lucro), criam, forjam uma relação de pertencimento com o território. Isso significa que o território não é apenas o espaço físico-geográfico explorado, mas, é também, o lugar de produzir memórias, histórias enredadas em suas espiritualidades. (DIEGUES, 2001; ACSERALD, 2010; COSTA, 2018)

São desse modo projetos antagônicos, que ao competir pelos mesmos recursos naturais, protagonizam diferentes conflitos agrários, inclusive patrocinados pelo grande capital e por falta de uma política de reforma agrária eficiente. Amparadas em Penha (2012), observamos que a reforma agrária vem sendo debatida desde 1960, tanto por intelectuais da área das ciências humanas e sociais como por políticos com interesses diversos. Não podemos olvidar que nesse período viveu-se no Brasil a chamada ditadura civil-militar, momento em que se fomentou uma política de concentração de enormes parcelas de terra da Amazônia nas mãos da iniciativa privada ao mesmo tempo em que se concederam incentivos fiscais para que fossem investidos na criação de gado bovino (PEREIRA, 2014).

$\mathrm{Na}$ década de 1980, a política de incentivos fiscais pela Superintendência de Desenvolvimento da Amazônia (SUDAM), órgão extinto, em 2001, valorizou de 1960 a 2001, o projeto latifúndio-monocultural, o que explica a concentração de terras nas mãos de poucos e implica nos dias atuais em reduzidas áreas protegidas, que pouco alteram a 
estrutura fundiária da região (COSTA, 2005). Ainda nesta década, especificamente em 1981 o estado criou a Política Nacional do Meio Ambiente, com critérios definidos para o licenciamento ambiental, que segundo Câmara (2013) deu-se de forma duvidosa, pois, diferentes empreendimentos foram aprovados quando não deveriam, causando, assim, sérios problemas em relação ao impacto ambiental.

Nesta década (1980), os Movimentos dos Trabalhadores Rurais Sem Terra (MST) começaram a se articular e a defender como principal bandeira, a reforma agrária, interpretada por este movimento como condição para os povos do campo habitar e produzir na terra com dignidade. É nesta época que ocorre a chamada democratização do país e, nessa dinâmica, a penetração do debate ecológico na agenda governamental, em vista de conciliar desenvolvimento e sustentabilidade. Toma corpo, assim, a ideia de políticas "sustentáveis", defendida pelos diferentes grupos sociais, como importante tática de reconhecimento da existência social dos diversos povos.

Almeida (2008), argumenta que as ações de mobilização dos movimentos sociais foram fortalecidas com a aprovação de dispositivos constitucionais e infraconstitucionais. Entre tais dispositivos destaca-se a Constituinte Federal (CF) de 1988, que dedica um capítulo para as questões ecológicas, colocando o meio ambiente como foco das decisões políticas. Além desse aspecto, a CF88, permitiu que as teorias do pluralismo jurídico, defendidas pelos grupos sociais, ganhassem força. Fato que leva Shiraishi Neto (2011), entender o pluralismo jurídico como condição para garantir o reconhecimento da diversidade social, resultado de um intenso processo de mobilização por direitos no mundo todo, e que confere aos povos tradicionais, condições de permanecer no território que tradicionalmente habitam e praticam. Um processo ameaçado pelo avanço da direita, base da política do atual governo.

Outro importante dispositivo nesse aspecto é o Decreto Legislativo n. 143, o qual procurou seguir a Convenção 169 da Organização Internacional do Trabalho (OIT), de junho de 1989. Este leva em consideração como critério e reconhecimento fundamental para povos tradicionais e terras tradicionais "os elementos de autoidentificação, reforçando, em certa medida, a lógica dos movimentos sociais" (DOURADO, 2010, p. 1314). O reconhecimento de autoidentificação da categoria povos tradicionais se intensificou na Amazônia, mas só foi possível devido ao trabalho coletivo das associações que surgiram e que se formaram levando em consideração além da autodefinição, a questão da consciência ambiental, fatores político-organizativos, e a identidade coletiva (ALMEIDA, 2008). 
Porém, esse reconhecimento jurídico-formal não foi de fácil aceitação, pois as categorias e as formas de apropriação de uso comum, antes invisíveis socialmente, surgiram trazendo uma transformação na estrutura agrária do país. Esse reconhecimento contribuiu com a visibilidade dos territórios e modos de vida dos povos tradicionais (LITTLE, 2002). O termo povos tradicionais, para Little (2002), deve levar em consideração, além da questão empírica e contexto histórico, a política, já que na realidade essas duas dimensões são praticamente inseparáveis. Na compreensão de Almeida (2008), a Convenção 169 da OIT favoreceu a redefinição da política agrária brasileira, além da aplicação da política ambiental e de políticas étnicas, que, em todo caso, reforçam a implementação da Convenção sobre a Diversidade Biológica (CDB), aprovada pelo Decreto legislativo N. 02/1994.

Em relação à política agrária, cabe lembrar que, somente após o regime ditatorial, especificamente, no governo de Fernando Henrique Cardoso que o Estado apresentou o I Plano Nacional da Reforma Agrária (I PNRA). Um plano que sob orientação dos organismos internacionais atendeu muito mais aos interesses capitalistas, que as necessidades do povo. Tal plano foi substituído no governo Lula pelo II PNRA, que diferentemente, do anterior abarcou agricultores familiares do MST, às populações ribeirinhas, comunidades rurais tradicionais, entre outros seguimentos da população habitantes dos espaços rurais (PENHA, 2012), influenciado pelas reivindicações sociais. Uma das possíveis críticas atribuídas à política em questão diz respeito a sua pseudo materialidade.

Em meio à essa trama territorial e pautado em modelos internacionais, o Brasil adotou uma política de conservação, por meio do Sistema Nacional de Conservação da natureza, que abrange as Unidades de Proteção Integral e as Unidades de Uso Sustentável (BRASIL, 2007a). A primeira, caracterizada por Litlle (2002) de preservacionista territorializante, prioriza a proteção integral e o uso indireto dos recursos naturais, sem a presença humana. A segunda, com foco na sustentabilidade, tem por objetivo o equilíbrio entre conservação da natureza e utilização de seus recursos em benefício da comunidade local, o que ocorre por meio da valorização da presença dos povos tradicionais nestas áreas. Estas unidades conciliam a proteção da fauna, da flora e a exploração de seus recursos para fins científicos, educacionais, recreativos e até turísticos (LITTLE, 2002).

No rastro dessa perspectiva tem-se como UC as Reservas Extrativistas e os Programas de Assentamento Agroflorestais (PAEx), os quais tem sido criado em áreas 
consideradas de proteção ambiental como este arquipélago, muitas vezes, sem o devido esclarecimento para as comunidades do que isso de fato representa. Contudo, entendese que as Reservas e os PAEx constituem-se tática importante para o reconhecimento das formas de apropriação e exploração dos povos tradicionais na manutenção da biodiversidade e garantia do desenvolvimento sustentável. Além de contribuir para a permanência desses povos no território.

Com tais UC, os povos tradicionais são vistos como "atores" responsáveis pela conservação e preservação do meio ambiente, e isso deve ocorrer por meio de uma parceria, ou melhor, de uma gestão partilhada. Para Diegues (2001) isso é possível porque os povos tradicionais possuem conhecimentos sobre a natureza que thes permitem manter seus modos de vida e favorecer a preservação dos recursos e da biodiversidade de seus respectivos territórios.

Little (2002, p. 18) nos lembra que a "dimensão ambientalista dos territórios sociais se expressa na sustentabilidade ecológica da ocupação por parte desses povos durante longos períodos de tempo, baseada nas formas de exploração pouco depredadoras de seus respectivos ecossistemas", fato que atesta-Ihes a condição de gestar o ambiente em partilha. Uma parceria que na compreensão de Acselrad (2010) pode representar a garantia de eficácia e legitimidade da conservação da natureza e sua riqueza.

Com efeito, direitos e garantias fundamentais acerca da UC, ficaram assegurados a partir da aprovação da Lei oㅡ 9985, em 18 de julho de 2000, que institui o Sistema Nacional de Unidades de Conservação da Natureza (SNUC), e garante a presença das populações tradicionais nas UC, bem como normatiza o uso dos recursos nessas unidades. Coaduna, assim, com a Convenção № 169/OIT, a qual entende os povos ou comunidades tradicionais como coletividades que possuem relação especial com seus territórios. Logo, à proteção ou conservação do ambiente não pode se dá de forma separada desses povos, pois suas identidades são indissociáveis do território (BRASIL, 2014).

Dentro dessa perspectiva, em muitos casos, na questão do uso de terras por povos tradicionais está presente o entendimento de variados termos como o "uso comum de terras", que são "formas de privatizar direitos sobre um objeto sem dividi-lo em pedaços" (MCKEAN; OSTROM, 2001, p. 87). Outro termo conforme Little (2002) refere-se à "noção de pertencimento", pois, muitos moradores ribeirinhos mantem relação de identidade a partir da ocupação de áreas "abandonadas". Esse pertencimento a qual Little (2002) menciona não está ligado somente a povos indígenas de uma área imemorial, mas, 
também, a grupos que surgiram historicamente numa área, como é o caso dos ribeirinhos do Mapuá, cuja maioria descende de migrantes nordestinos que chegaram no Mapuá no início do século XX, fugindo da seca no Ceará.

No Estado do Pará, desde 1989 o Arquipélago do Marajó forma uma Área de Proteção Ambiental, com vista a preservação da rica biodiversidade presente neste território. A partir de então sob o prisma da sustentabilidade e, também, do preservacionismo, foram criadas seis reservas extrativistas, um parque ${ }^{2}$ e 114 PAEx (COSTA, 2019), com o intuito de garantir a mencionada preservação, além de dimensionar a política territorial dessa porção da Amazônia. O PDTSAM, aprovado em 2007, em vista de tal finalidade, apresenta algumas diretrizes ditas como prioritárias. Dentre elas destacamos as que tratam exclusivamente do ordenamento territorial, regularização fundiária e gestão ambiental, que são: 1) Promover a regularização fundiária; 2) Promover a exploração dos recursos florestais respeitados os preceitos da preservação, conservação e manejo controlado desses recursos; e 3) Promover a criação e a implementação das UC (BRASIL, 2007b).

A primeira diretriz tem a função de expedir "Termo de Autorização de Uso (TAU) e licenciamento ambiental para população ribeirinha tradicional em áreas de várzea, terrenos de marinha e acrescidos, cujo produto final será a Concessão do Direito Real de Uso em Resex, PAEx, envolvendo também as áreas centrais” (BRASIL, 2007b, p. 21). TAU é tido como estratégia para o Estado ajustar e organizar a vida de cada família que vivem às margens dos rios, o que pode significar o uso legal do espaço agrário, evitando assim o risco de serem expulsos. A segunda tem a função de atuar na promoção da educação ambiental, objetivando a utilização adequada dos recursos florestais, bem como o incentivo do manejo sustentável dos recursos naturais e a recuperação de áreas degradadas, com espécies nativas, através de sistemas agroflorestais. Diante deste empreendimento, a população ribeirinha pode desfrutar dos recursos florestais, mas com o compromisso da preservação e conservação da mata nativa.

2 Em 2009 o governo estadual criou o Parque Estadual de Charapucu dentro da área de assentamento do Incra de mesmo nome. Nesta área existem 110 famílias, o que pela legislação não deveriam estar ali. Um erro grave do governo, o que ocorreu devido à realização de audiências públicas não satisfatória. O Ministério Público Estadual foi chamado para intervir nessa questão, e diante disso foi criado um Termo de Ajustamento de Conduta entre o governo do Estado do Pará, o Incra e a SPU para tentar ajustar o parque, ou seja, diminui-lo para comportar as 110 famílias. Existe ainda a possibilidade de tornar o parque em reserva extrativista. Mas, devido uma ação da SEMA de fiscalização, onde fiscais invadiram casas de moradoras, prenderam motosserras, etc., o diálogo entre as comunidades locais, o Sindicato e o governo do Estado ficou estremecido (C.P. R., 2016). 
A terceira diretriz, converge para a criação e a implementação das UC, reforçando o que assegura a Lei no 9985 de 18/07/2000. Tais UC são tidas por este plano como forte aliada para a conservação da natureza, do uso sustentável e extrativista da população ribeirinha. São ainda elementos que contribuem para a conservação da biodiversidade e proteção das populações tradicionais e seus conhecimentos, o que a torna objetos de ações de fortalecimento com estruturação institucional, planos de manejo e mobilização comunitária (BRASIL, 2007b).

Nos últimos anos, a partir deste plano e das leis que amparam a criação de UC, o estado criou, no Marajó, sem a devida divulgação e esclarecimento à população os PAEx. Isso mostra que a criação dessas unidades, na maioria, dos casos, configura-se como imposição do Estado e não uma reivindicação das famílias, que, aliás, desconhecem o real significado de um PAEx. Ação que em diferentes situações tem implicado em conflitos entre famílias assentadas e madeireiros, os quais não reconhecem os assentamentos, por se intitularem "donos da terra", bem como "patrões" dos moradores, o que indica a fragilidade da política.

Situação semelhante ocorre nas Reservas Extrativistas, criadas na mesma lógica dos PAEx, a exceção parece ser a Resex-Mapuá, criada após solicitação das comunidades locais, como veremos no próximo tópico. Essas UC em geral, enfrentam problemas, até mesmo porque o TAU não garante as famílias segurança, que lhes permita resolver os conflitos com empresários da região pelo acesso e uso dos recursos da floresta. Esse instrumento é visto como letra morta pelos madeireiros e latifundiários. Daí Acevedo-Marin (2015) afirmar que a regularização fundiária na Amazônia confunde direito com benesses, uma prática não separada das práticas adotadas pelo clientelismo, praticado no Marajó por séculos.

\section{RESEX - MAPUÁ: POR QUE CRIAR DE UMA RESERVA EXTRATIVISTA?}

A Reserva Extrativista Mapuá (Resex-Mapuá), criada por meio de Decreto Presidencial s/n de 20/05/2005, no município de Breves, arquipélago de Marajó, possui uma área de 94.463,03 hectares. Encontra-se localizada às margens dos rios Mapuá e Aramã, na porção leste desse município, no limite com os municípios de Anajás, São Sebastião da Boa Vista e Curralinho. Conforme o Art. $2^{\circ}$ do decreto presidencial, a 
reserva foi criada com o "objetivo de proteger o meio ambiente e garantir a utilização dos recursos naturais renováveis, tradicionalmente utilizados pela população extrativista, residente na área de sua abrangência" (BRASIL, 2005).

Nesta região, em 2017, encontrava-se cerca de 900 famílias (LEITE, 2017) organizadas em 14 comunidades de pequena escala (BEZERRA, 2011), a saber: Bom Jesus, Santíssima Trindade; São Sebastião do Mapuá, Nossa Senhora das Graças/Vila Amélia, Santa Rita, São José, São Benedito, São Sebastião do Canta Galo, Santa Maria, São Sebastião do Mapuá-Miri, Assembleia de Deus, Nossa Senhora de Nazaré, Perpétuo Socorro, Nazaré do Socó (Figura 1). A disposição espacial do território é classificada localmente em Baixo, Médio e Alto Mapuá, o Baixo vai da área que compreende a entrada do rio, chamado de "boca" pelos moradores, até o início da comunidade Nossa Senhora das Graças, conhecida por vila Amélia. Nesta área estão as comunidades São Sebastião do Mapuá-Miri e Bom Jesus.

Figura 1: Mapa de Localização da Resex-Mapuá e comunidades

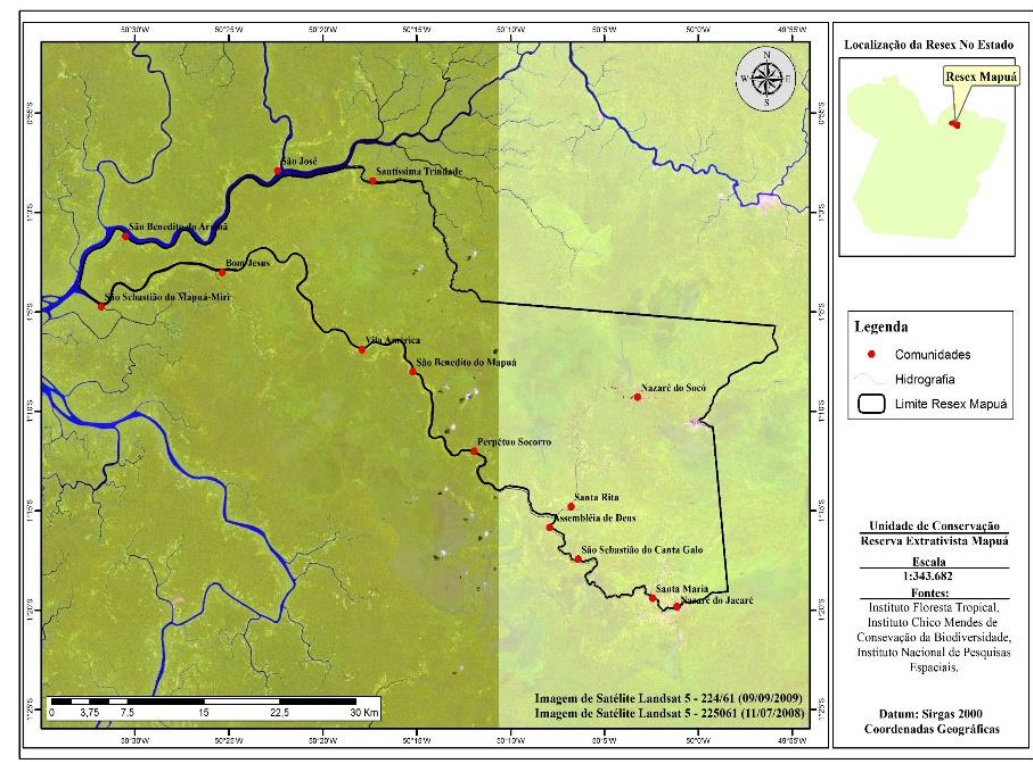

Fonte: ICMBio, 2009.

O Médio Mapuá, concentra-se as comunidades Nossa Senhora das Graças/vila Amélia, São Benedito do Mapuá e Perpétuo Socorro. Essa área tem início na vila Amélia e finaliza na comunidade Perpétuo Socorro. E o Alto Mapuá é formado pela área que agrega as cabeceiras do rio em duas direções: lago do Jacaré à esquerda e lago do Socó à direita. Nesta área estão as comunidades Santa Rita, São José, Assembleia de Deus, São Sebastião do Canta Galo, Santa Maria, Perpétuo Socorro do Canaticum e Nossa 
Senhora de Nazaré, conhecida como Nazaré do Jacaré (Figura 1). Uma parte desse espaço (sobretudo os lagos) durante o verão amazônico ${ }^{3}$, especialmente, nos meses de outubro, novembro e início de dezembro apresenta o nível da água mais baixo, o que impossibilita a mobilidade entre as comunidades.

Registra-se que 0 acesso às comunidades se dá somente através do transporte fluviomarítimo, com destaque para barcos, rabetas (canoas pequenas com motor suspenso na popa) e lanchas. A principal rota para chegar ao Mapuá, saindo do núcleo urbano de Breves, abrange os rios Parauau, Jaburu, Macacos e Aramã, bem como diferentes rios menores e furos. Esta UC é administrada por um Conselho Deliberativo, instituído pela Portaria ํㅜ 39, de 25/06/2008, composto por representantes da sociedade civil organizada e ribeirinhos que vivem na área da reserva. É presidido pelo ICMbio, órgão federal responsável pela gestão das UCs, o qual designa a cada dois anos um técnico para ocupar a função de gestor. Na comunidade Bom Jesus encontra-se a Sede da Associação dos Moradores da Resex-Mapuá (Amorema), organização representativa, criada em 04 de novembro de 2005, e presidida inicialmente pelo líder comunitário A.G.

Com a pesquisa identificamos que as famílias no Mapuá vivem do trabalho com o extrativismo e a agricultura de subsistência (mandioca, milho, banana etc.), além da criação de animais de pequeno porte (porcos, galinhas etc.); da caça e pesca artesanal (ocorre especialmente de julho a outubro, quando os lagos, ficam cheios de peixes). A economia local é alimentada pela produção e comercialização do açaí (Euterpe oleracea Mart.) e farinha de mandioca, bem como pela exploração do palmito de açaí e da madeira. $\mathrm{O}$ açaí (coletado de junho a agosto) e a farinha (produzida o ano todo) são os principais itens alimentar, além de serem a moeda de troca entre as famílias e os "regatões"/comerciantes ambulantes que frequentam o local.

Com a criação da reserva, a extração da madeira e do palmito passou a ser atividade "proibida" sem o devido manejo. Isso para muitos moradores é um desafio, pois é o trabalho que sabem fazer. Dumora (2006) esclarece que em UC o uso do território deve atender as normas estabelecidas em planos de manejo, documento que deve ser construído com a participação dos moradores local. Nesse documento, muitas "práticas antigas" consideradas predatórias passam a ser proibidas, fato que ao menos em tese

${ }^{3} \mathrm{Na}$ região Norte, diferentemente, das demais regiões brasileiras que compreendem as quatro estações, o clima de característica equatorial envolve duas estações, que no caso do Marajó, é popularmente chamado de inverno e verão amazônico ou marajoara para definir o período das chuvas, que ocorrem geralmente em meados de dezembro a junho e do sol, de junho ao início de dezembro. 
leva as famílias recorrerem a outras estratégias, ressignificando assim suas práticas e relação com o território.

Vale lembrar que quando se trata de povos tradicionais e de seus territórios, os mesmos se baseiam em décadas, séculos de ocupação efetiva, que acabam por levar em consideração não somente a questão legal, mas, também a "memória coletiva que incorpora dimensões simbólicas e identitárias na relação do grupo com sua área, o que dá profundidade e consistência temporal ao território" (LITTLE, 2002, p.11). Ressalta a entrevistada M. G, que algumas práticas mesmo proibidas, a exemplo da tapagem ${ }^{4} \mathrm{e}$ da exploração da madeira, continuam sendo praticadas, em função da sobrevivência. Porém, a maioria das famílias já começaram a perceber que precisam criar outras estratégias para melhor cuidar do território, que, também, significa zelar e garantir a sobrevivência das gerações futuras.

Como relatado pelos moradores entrevistados esta UC é, na verdade, tática que encontram para continuarem no território habitado, logo, cuidar é um compromisso de todos, mencionou a interlocutora. R.N. Esta depoente e os demais lembram que por longas décadas o Mapuá ficou sob o domínio dos empresários, que se intitulavam donos do território e patrões das famílias. Nos relatos identificamos que nos anos iniciais do século XX, durante o ciclo da borracha migraram para esse território muitos cearenses que ao chegar foram trabalhar nas colocações da borracha, sob um poderoso esquema de vigilância e controle dos "coronéis do Mapuá" (empresários da borracha que na época se intitulavam coronéis, patente que compravam para intimidar os subordinados). Desde então o Mapuá tornou-se o "lugar do cativeiro", nas palavras de seu J.H. Conta esse narrador que ninguém podia chegar a "boca" do rio sem a autorização do patrão.

Dentro dessa lógica que os cearenses e seus descendentes, os quais formam a maioria das famílias que hoje estão no Mapuá, viveram e trabalharam por muitos anos. No final da década de 1990, esses ribeirinhos, além de viverem na condição de escravos, foram ameaçados de serem expulsos do território, pois o patrão, alegando crise econômica, vendeu as terras do Mapuá a um grupo de empresários, liderado por um chinês. Este novo dono, almejando criar uma reserva sustentável particular impôs sanções aos moradores e os ameaçou de expulsão. Para melhor entender esse enredo mergulhamos na narrativa abaixo:

${ }^{4}$ Espécie de tapume feita com varinhas, confeccionadas da árvore do arumã (vegetal específico da região amazônica), para represar rios e igarapés com a finalidade de reter os peixes. 
Em 89 [1989] surgiu uma polêmica aqui dentro, foi sobre os moradores e o patrão, lá no lago do Jacaré. Daqui a oito horas de tempo a gente chega lá de barquinho. [...]. Tinha que passar uma madeira e o patrão não deixava, dizia que nós só passava se fosse de avião. Eu como representante sindicalista do povo, disse não, não tem avião que traga mil tora de pau aí por cima. Então disse, mais nós vamos passar. Aí reunimos, na época nós era 42 pessoas sócios do Sindicato do Trabalhador Rural, desci em Breves falei com o presidente do sindicato dos trabalhador, na época era o RPA, ligamos para o nosso advogado de Belém aí ele autorizou que a gente fosse com a juíza e pegasse uma autorização por 15 dias pra baixar com a madeira, mas que mobilizassem que a ameaça estava grande de guerra. Podia passar, mas que um ia ter que ficar, então, era uma ameaça grande. Sindicalista não tem medo de nada, ele sabe que tem vida, mas ele tem que defender o companheiro. Aí reunimos 40 pessoas e nos fomos, trabalhamos e passamos a madeira, com ordem autorizada da juíza, porque ninguém pode prender o trabalho do trabalhador, por isso não, aí a gente conseguiu passar foi a primeira vitória. Aí veio 99, 2000, 2001 começou, o patrão tinha vendido a terra pro chinês (em 99 já tinha vendido as terras) aí em 2001 ele veio pra tomar a posse do terreno, mas com ameaça que o povo não podia tirar a madeira, não podia fazer roça. [...] com todas essas ambições ele veio, não podia ser feito nada disso porque ele era o dono da terra. [...]. Fomos fizemos uma passeata em Breves que foi uma polêmica, o certo que ele estava presente. Entrou o sindicato, entrou outras entidades e a comunidade. A comunidade sempre toda, todo tempo, foi o apoio e aí a gente ganhou. [...] O advogado disse vamos preparar um abaixo assinado e mandar pra Brasília. [...] agente preparou o abaixo assinado em 2003 prontinho, 2004 ele seguiu, em 2005 foi quando - Luiz Inácio assumiu a presidência aí mandou chamar já pra receber o decreto, aí 20 de maio de 2005 foi decretado a RESEX MAPUA, e em 5 de novembro foi fundada a Associação AMOREMA que é associação mãe de toda a RESEX MAPUA e eu fui o primeiro presidente escolhido. [...] em 2007 foi criado o Instituto Chico Mendes de conservação da biodiversidade que gerencia as reservas. Eu estava em Brasília quando se designou o gestor da Resex Mapuá. O primeiro gestor foi o DM e a EC que veio justamente para fazer a primeira gestão em Mapuá. Aí já era o ICMbio que já estava comandando como gestor pra ajudar a mobilização e todo o processo (A.G. 64a, 2017).

A longa narrativa, reafirmada pelos demais interlocutores, demonstra que a criação da Resex foi precedida por luta e conflito. De um lado os ribeirinhos, tradicionais moradores, defendo o direito de uso dos recursos e da terra como condição de sua sobrevivência, e de outro lado, o empresário, que se intitulando dono da terra e dos recursos ameaça e proíbe os ribeirinhos. O desfecho desse conflito dá-se com a criação da Resex, que como indicado atende a reivindicação da população como medida para livrar-se do empresário/patrão e garantir o direito ao uso sustentável do território tradicionalmente ocupado.

O medo da perda do território foi em tese afastado com a criação da reserva, contudo novos conflitos surgiram, agora quanto ao uso do território considerando as 
normas e regras estabelecidas. Após, instituição da reserva, os entrevistados relataram que o primeiro passo foi estabelecer um plano de uso. Este plano foi conduzido por técnicos do ICMbio e toda sua elaboração levou em torno de um ano e seis meses. Nesse processo, de acordo com o entrevistado O. M. buscou-se "conhecer junto aos moradores os costumes tradicionais" culturalmente herdados, além disso, "delimitou-se as áreas de uso familiar e de uso comum de cada família", tendo por base o limite dos igarapés. Também ficou definido que a retirada da madeira e do palmito só poderia ocorrer mediante um plano de manejo, orientado pelo ICMbio, para atender necessidades básicas dos moradores. Conforme este plano, a roça na área de mata e a tapagem são práticas proibidas como tudo que possa representar ameaça para o uso sustentável dos recursos (BRASIL, 2009).

Tais impeditivos como mencionado anteriormente são vistos por alguns dos entrevistados como conflitivos, pois são medidas importantes, mas que não levam em consideração as condições materiais e econômicas das famílias, o que justifica a continuidade das atividades. Ainda na linha do conflito identifica-se a presença dos próprios empresários que continuam por perto e inclusive financiando a retirada "ilegal' da madeira. Todavia, com esta UC as famílias têm a liberdade para produzir e comercializar, assim como passaram a ter acesso a direitos antes negados, a exemplo da aposentadoria, ter documentos, participar de programas sociais, etc.

É fato que estes povos ao longo dos anos estabeleceram suas formas de se relacionar com o rio, a floresta e a terra, o que seguramente deve ser observado pela Resex. Aliás, o rio e sua dinâmica ambiental imprime o ritmo de vida desses moradores. No inverno amazônico com o aumento do volume de água grande parte, das áreas de terras mais baixas, ficam embaixo da água, o que condiciona de forma decisiva (mas, não determina), o modo de vida das famílias ribeirinhas, caracterizado pela forma como se organizam e realizam suas atividades de subsistências. De igual modo, no verão amazônico quando o volume de água diminui e parte do rio vira caminho de terra e lama, outras formas de atividades são realizadas tais como o plantio da roça, estabelecendo formas do saber-fazer dos ribeirinhos na relação com o natural.

De acordo com Figueiredo e D’ávila (2015, p. 196), o “agir no mundo rural pode ser hoje a oportunidade para acionar a reinstalação do dado sensível, recuperando autonomia e qualidade dos lugares a partir de suas singularidades, para resistir ao projeto de total unificação da lógica da globalização" [grifos do autor], que tem como fundamento a exploração. O modo de vida ribeirinho na Amazônia ainda que não passe despercebido 
da lógica perversa do capital e não abarque as totalidades da dinâmica de vida dos diferentes grupos no mundo, permite demonstrar e chamar atenção para a necessidade de entender a natureza não somente como espaço geográfico a ser explorado em função do lucro, mas que possamos percebê-la como espaço de vida, cultura, histórias e memórias.

\section{CONSIDERAÇÕES FINAIS}

O texto tentou evidenciar a luta dos ribeirinhos do rio Mapuá, em Breves, no Marajó, com empresários da madeira pelo uso, acesso e permanência no território tradicionalmente habitado. Nesse enredo, a criação de uma UC foi a principal medida requerida pelos ribeirinhos para libertarem-se das ameaças dos empresários que se intitulavam donos da terra e patrão das famílias. Diante da tessitura apresentada, analisase que o grupo demonstrou consciência coletiva sobre seu papel social no que tange a afirmação e reafirmação do direito de permanecer no território.

Diante dos questionamentos levantados e dos resultados apresentados ao longo do texto, evidencia-se que a questão ambiental e agrária da região Amazônica, em especial, do Marajó, não é tratada pelo Estado como prioridade para atender as necessidades das populações tradicionais, e, sim, como estratégia para atender os interesses capitalista. Daí perceber que mesmo sendo criadas as UC, os conflitos históricos entre os grupos (a exemplo dos ribeirinhos e madeireiros) não foram superados.

No Mapuá, mesmo os conflitos não sendo superados, é bom considerar que a UC significou a principal medida para os ribeirinhos libertam-se do mandonismo e ameaça dos empresários, denominados de patrões. Porém, por outro lado, tem o desafio agora de saber lidar com as normas da Resex e com a configuração de novas práticas. Mas, para, além disso, o desafio também é lidar com a política agrária e ambiental, sobretudo, quando os interesses externos, isto é, de empresários pelos recursos permanecem. Não podemos olvidar que a política fundiária tem ranços neoliberal, logo as UC podem representar uma ameaça para o crescimento quase que desenfreado do agronegócio, o que explica o descaso do Estado. Mas por outro lado, essas UC podem se transformar em espaços estratégicos do capital.

Há nesse movimento um importante aspecto que não podemos deixar de considerar, que é o tempo de existência da Resex, fator que em nosso entendimento não 
permite tirar algo conclusivo em relação a mudanças mais sistemáticas no modo de se relacionar com o ambiente e cuidar dos recursos de forma responsável e sustentável. Embora isso, entendermos que a Resex-Mapuá para os ribeirinhos é uma tática política de afirmação e reafirmação do direito de permanecer no território que tradicionalmente habitam e costuram seus modos de vida. Essa UC é ainda condição para que esses povos possam ressignificar sua relação com a natureza. Consideramos que a atuação consciente desses sujeitos é estratégia importante para se criar e reconhecer novas territorialidades e, desse modo, impedir o aumento de índices alarmantes como a pobreza, desigualdades, conflitos, etc., elementos que tem ajudado atribuir ao Marajó, a fama de pior lugar para se morar no Brasil.

\section{REFERÊNCIAS}

ACEVEDO-MARIN, R. Debates e discursos em torno do Plano de Desenvolvimento Territorial Sustentável do Marajó. In: ACEVEDO-MARIN, R. E.; TELES, E.; CARDOSO, M. do S. C.; SANTOS, D. B. dos. (Org.). Povos Tradicionais no Arquipélago de Marajó e políticas de ordenamento territorial ambiental. Rio de Janeiro: Casa 8. 2015. pp. 2338.

ACSERALD, H. Cartografia social e dinâmicas territoriais: marcos para o debate. Rio de Janeiro: Universidade Federal do Rio de Janeiro, Instituto de Pesquisa e Planejamento Urbano e Regional, 2010.

ALMEIDA, A. W; e B. Terras de quilombos, terras indígenas, "babaçuais livre", "castanhais do povo", "faxinais e fundos de pasto: Terras tradicionalmente ocupadas. 2. ed. Manaus, PGSCA -UFAM. 2008.

BEZERRA, M. "As moedas dos índios": um estudo de caso sobre os significados do patrimônio arqueológico para os moradores da Vila de Joanes, ilha de Marajó, Brasil. Bol. Mus. Para. Emílio Goeldi. Cienc. Hum. vol. 6, n. 1, pp: 57-70, 2011.

BRASIL. Ministério Público Federal. Câmara de Coordenação e Revisão. Territórios de povos e comunidades tradicionais e as unidades de conservação de proteção integral: alternativas para o asseguramento de direitos socioambientais. Câmara de Coordenação e Revisão; coordenação Maria Luiza Grabner; redação Eliane Simões, Débora Stucchi. - Brasília: MPF, 2014.

BRASIL. Instituto Chico Mendes de Conservação da Biodiversidade (ICMBio). Plano de Manejo Participativo da Reserva Extrativista Mapuá - Fase I. Breves (PA), 2009

BRASIL. DECRETO № 6.040, DE 7 DE FEVEREIRO DE 2007a. Institui a Política Nacional de Desenvolvimento Sustentável dos Povos e Comunidades Tradicionais, 
2007a. Disponível em: http://www.planalto.gov.br/ccivil_03/_ato2007-

2010/2007/decreto/d6040.htm. Acesso em: 20 fev. 2015

\section{BRASIL. PLANO DE DESENVOLVIMENTO TERRITORIAL DO ARQUIPÉLAGO DO}

MARAJÓ, 2007b. Disponível em: http://sit.mda.gov.br/download/ra/ra129.pdf. Acesso em: 20 fev. 2019.

BRASIL. Presidência da República. DECRETO DE 20 DE MAIO DE 2005. Disponível em: https://www.planalto.gov.br/ccivil_03/_Ato2004-2006/2005/Dnn/Dnn10533.htm. Acesso em: 15 mar. 2019.

COSTA, E. M. OS "POVOS RIBEIRINHOS" E A RESERVA EXTRATIVISTA NO RIO MAPUA NO ARQUIPÉLAGO DE MARAJÓ, BRASIL. In: CASTILHO, Danila Barbosa de (org.). A interlocução de saberes na antropologia. Ponta Grossa (PR):

Atena Editora, 2019. p.67-83. Disponível em:

https://www.atenaeditora.com.br/arquivos/ebooks/a-interlocucao-de-saberes-naantropologia. Acesso em: 20 set. 2019.

COSTA, E. M. MEMÓRIAS EM ESCAVAÇÕES: Narrativas de Moradores do rio Mapuá sobre os Modos de Vida, Cultura Material e Preservação do Patrimônio Arqueológico (Marajó, PA, Brasil). 334 f. 2018. Tese (Doutorado) - Programa de Pós-graduação em Antropologia (PPGA), da Universidade Federal do Pará, Belém, 2018.

COSTA, F. A. Questão Agrária e Macropolíticas na Amazônia. Estudos Avançados, vol.19 n.53, pp: 131-156, 2005. Disponível em: http://www.scielo.br/scielo.php?script=sci_arttext\&pid=S0103-40142005000100009. Acesso em: 15 out. 2019.

DIEGUES, A. C. S. O MITO MODERNO DA NATUREZA INTOCADA. 3. ed. São Paulo: EDITORA HUCITEC, 2001.

DOURADO, S. B. Os conhecimentos tradicionais como objeto de disputas no campo: a diversidade dos sentidos relacionais. In: ALMEIDA, A. W. B. de (Org.) Conhecimentos Tradicionais e territórios na Pan-Amazonia. Manaus, UEA. Editores, 2010. Caderno de Debates Nova Cartografia Social (p.55-63).

DUMORA, C. Viver e sobreviver numa Área de Proteção Ambiental: o caso da pequena agricultura familiar em uma das comunidades rurais da APA de Guaraqueçaba.

Desenvolvimento e Meio Ambiente, n. 14, p. 47-67, jul./dez. Editora UFPR, 2006.

FIGUEIREDO, C. M; D'AVILA NETO, M. I. Dinâmicas identitárias, no rural -urbano-rural: Território e fronteira entre agricultores do Rio de Janeiro. Revista Internacional Interdisciplinar INTERthesis, vol. 12, n. 2, pp: 180-199, 2015. Disponível em: https://periodicos.ufsc.br/index.php/interthesis/article/view/1807-1384.2015v12n2p180. Acesso em: 20 set.2019.

LITTLE P. E. Territórios sociais e povos tradicionais no Brasil: Por uma antropologia da territorialidade. Universidade de Brasília. 2002. 
MCKEAN, M.; OSTROM, E. Regime de propriedade comum em florestas: somente uma relíquia do passado? In: DIEGUES, A. C.; MOREIRA, A. C. C. (Org.) Espaços e recursos naturais de uso comum. São Paulo: USP, 2001. (p. 79-96).

\section{PEREIRA, A. dos R. COLONIZAÇÃO E CONFLITOS NA TRANSAMAZÔNICA EM TEMPOS DA DITADURA CIVIL-MILITAR BRASILEIRA. CLIO - REVISTA DE PESQUISA HISTÓRICA, n. 31, vol. 2, pp:1-17, 2014.}

\section{PENHA, L. Reforma Agrária na Amazônia? Avaliação do II Plano Nacional de}

Reforma Agrária no Território Rural do Baixo Tocantins - PA. 2012. 133f. Dissertação (Mestrado em Desenvolvimento Sustentável). Programa de Pós-graduação em

Desenvolvimento Sustentável do Trópico Úmido, Núcleo de Altos Estudos Amazônicos da Universidade Federal do Pará, Belém, 2012. Disponível em:

http://www.ppgdstu.propesp.ufpa.br/ARQUIVOS/Dissertacoes/2012/Luciano\%20Rocha\%2 0da\%20Penha.pdf. Acesso em: 12 set. 2019.

SHIRAISHI NETO, J. "Novas" "Sensibilidades" Velhas Decisões: notas sobre as transformações jurídicas recentes. Sequência, n.62, pp: 79-96, 2011.

\section{NOTAS}

Eliane Miranda Costa

Doutora em Antropologia

Universidade Federal do Pará, Campus Universitário do Marajó-Breves, Faculdade de Educação e Ciências Humanas, Breves, Pará elyany2007@hotmail.com

(ID) https://orcid.org/0000-0001-6747-4639

Vivianne Nunes da Silva Caetano

Doutora em Antropologia

Universidade Federal do Pará, Campus Universitário do Marajó-Breves, Faculdade de Educação e Ciências Humanas, Breves, Pará vns@ufpa.br

https://orcid.org/0000-0003-3808-7618

(1D)

Endereço de correspondência do principal autor

Faculdade de Educação e Ciências Humanas - FECH

Campus Universitário do Marajó-Breves - CUMB

Alameda 4- Parque Universitário - Breves-Pará

CEP 68800-000, fone/fax $913783-1129$ ramais 240 e 241

\section{AGRADECIMENTOS}

Interlocutores da pesquisa;

Universidade Federal do Para;

Faculdade de Educação e Ciências Humanas - FECH.

\section{CONTRIBUIÇÃO DE AUTORIA}

Concepção e elaboração do manuscrito: E. M. Costa, V. N. da S. Caetano.

Coleta de dados: E. M. Costa, V. N. da S. Caetano.

Análise de dados: E. M. Costa, V. N. da S. Caetano.

Discussão dos resultados: E. M. Costa, V. N. da S. Caetano.

Revisão e aprovação: E. M. Costa, V. N. da S. Caetano.

\section{CONJUNTO DE DADOS DE PESQUISA}

Todo o conjunto de dados que dá suporte aos resultados deste estudo foi publicado no próprio artigo.

FINANCIAMENTO

NÃO SE APLICA. 


\section{CONSENTIMENTO DE USO DE IMAGEM}

NÃO SE APLICA.

\section{APROVAÇÃO DE COMITÊ DE ÉTICA EM PESQUISA}

NÃO SE APLICA.

\section{CONFLITO DE INTERESSES}

NÃO SE APLICA.

LICENÇA DE USO - uso exclusivo da revista

Os autores cedem à Revista Internacional Interdisciplinar INTERthesis os direitos exclusivos de primeira publicação, com o trabalho simultaneamente licenciado sob a Licença Creative Commons Attribution (CC BY) 4.0 International. Estra licença permite que terceiros remixem, adaptem e criem a partir do trabalho publicado, atribuindo o devido crédito de autoria e publicação inicial neste periódico. Os autores têm autorização para assumir contratos adicionais separadamente, para distribuição não exclusiva da versão do trabalho publicada neste periódico (ex.: publicar em repositório institucional, em site pessoal, publicar uma tradução, ou como capítulo de livro), com reconhecimento de autoria e publicação inicial neste periódico.

PUBLISHER - uso exclusivo da revista

Universidade Federal de Santa Catarina. Programa de Pós-graduação Interdisciplinar em Ciências Humanas. Publicação no Portal de Periódicos UFSC. As ideias expressadas neste artigo são de responsabilidade de seus autores, não representando, necessariamente, a opinião dos editores ou da universidade.

\section{EDITORES}

Javier Ignacio Vernal, Silmara Cimbalista e Selvino José Assmann (In Memoriam).

\section{LATT}

HISTÓRICO - uso exclusivo da revista

Recebido em: 20.11.2019 - Aprovado em: 05-02-2020 - Publicado em: 26-02-2020 